\title{
Ethos and Practice of a Connected Learning Movement: Interpreting Virtually Connecting Through Alignment with Theory and Survey Results
}

\author{
Maha Bali \\ American University of Cairo \\ Autumm Caines \\ Capital University \\ Helen DeWaard \\ Lakehead University \\ Rebecca J. Hogue \\ University of Ottawa \\ University of Massachusetts-Boston
}

\begin{abstract}
Virtually Connecting (VC) is a connected learning volunteer movement that enlivens virtual conference experiences by partnering those that are at the conference with virtual participants that cannot attend. In looking to articulate the ethos and intentions of VC, a manifesto was developed by a group of core members and presented at the Digital Learning Research Network in 2015. This paper connects the group's ethos, as defined in this manifesto, to various learning theories including Connectivism, connected learning, and the practice of online communities. The paper reports on both quantitative and qualitative results from a survey sent to members of the community over February and March of 2016, as well as some information obtained from blogs and other forms of social media, and ties these results to the manifesto items. This alignment of theory and participant feedback shows continuity between the stated ethos of the community and the impressions of those living the volunteer experience.
\end{abstract}

Keywords: learning community; synchronous; video 


\section{Introduction}

Academic conferences serve as hubs of information-temporary in time and space-for sharing research findings, case studies, best practices, and possible next steps through the conference sessions led by experts in the field. Informal conversations that occur outside of the scheduled organized sessions are an essential yet overlooked knowledge-sharing aspect of conferences. Because of their social nature, these interactions create and disseminate knowledge in a different way than what occurs inside the scheduled sessions. Through conversations, these interactions create a narrative that spreads knowledge through the development of social and topical connections. Though often thought of as an implicit benefit to the physical conference experience, these informal networking and learning opportunities of career academics are seldom studied or engaged with from a research perspective. A paper from McIntyre, Millar, and Thomas (2007) recognized the importance of networking at conferences and suggested increasing opportunities for networking via offering social opportunities for participants to engage, but this very brief and did not study the phenomenon. Physical attendance at conferences is inherently biased, as there are many who cannot attend due to barriers and restrictions of time, money, family, geography, and other commitments. There have recently been some attempts to provide access to those who cannot attend the organized sessions such as through video streaming and moderators taking questions from virtual participants. However, there have been very few, if any, attempts to bring these informal social-learning interactions to those that cannot attend the conference. Twitter has become a very small way of doing so, but there have been few attempts to study those endeavors (Djuricich \& Zee-Cheng, 2015; Shiffmann, 2012).

Virtually Connecting (VC) was created to engage individuals and groups in virtual participation at academic conferences thus widening access for those who cannot be physically present. VC is a grassroots-connected and Connectivist learning movement powered by a team of volunteers. It is designed to be open and free to all who wish to participate. Using emerging technologies, VC connects onsite conference presenters and attendees with virtual participants in small groups using online video conferencing tools, typically Hangouts on Air (Google Inc., Mountain CA). As a result, we refer to VC sessions as hangouts. VC therefore allows virtual conference participants to meet and talk with conference presenters and attendees in what often feels like spontaneous hallway conversations. There is room for ten connected devices in each virtual conversation - the limitation of Google hangouts on air. Each connected device could have more than one person sharing a camera/speaker/mic. Sessions are recorded and livestreamed whenever possible to allow additional virtual attendees to participate in the discussion by listening and asking questions via Twitter.

In this paper, we will explore the VC connected learning movement, which focuses on increasing access to these informal conversations by participants who otherwise would be unable to contribute to the collective discussion in this way. We will share results from a recent survey of VC affiliates and align them with the movement's core values as stated in the manifesto (n.d., Virtually Connecting). The manifesto was unpublished at the time of conducting the survey but had been presented at the Digital Learning Research Network conference (dLRN15) in October, 2015. 


\section{Literature Review}

In defining $\mathrm{VC}$ as a connected learning movement, we aligned VC's ethos with the learning theories of Connected learning (Ito et al., 2013) and Connectivism (Siemens, 2004). Additionally, we aligned VC's practice with that of Rheingold's (2012) analysis of virtual communities. VC was not founded with these theories or practices specifically in mind, and it is this alignment which highlights the novelty of this research. In this short literature review, we will give an overview of these theories and practices.

Both Connectivism and Connected Learning theories focus on a variety of shifts happening around modern approaches to learning that are precipitated by changes in modern technologies and challenge traditional learning theories. Connected Learning creates a framework for learning with a focus on equal opportunities to participate through social connections and interest-powered engagement (Connected Learning Alliance, undated).

Connectivism draws from several other theories including Chaos, Network, Selforganization, and Complexity theories. It focuses on the acquisition of knowledge in shifting and uncertain environments through networks synthesized by individuals. This is then fed into organizations and institutions, ultimately cycling back through network connections and continuing to nourish the individual learner. There are eight principles of Connectivism as laid out by Siemens (2004):

- Learning and knowledge rest in diversity of opinions.

- Learning is a process of connecting specialized nodes or information sources.

- Learning may reside in non-human appliances.

- The capacity to know more is more critical than what is currently known.

- Nurturing and maintaining connections is needed to facilitate continual learning.

- The Ability to see connections between fields, ideas, and concepts is a core skill.

- Currency (accurate, up-to-date knowledge) is the intent of all Connectivist learning activities.

- Decision-making is itself a learning process. Choosing what to learn and the meaning of incoming information is seen through the lens of a shifting reality. While there is a right answer now, it may be wrong tomorrow due to alterations in the information climate affecting the decision.

Rheingold (1993; 2012) provided several insights into the practices of virtual communities through decades of lived experience participating, learning, and socializing inside of them. Through analysis of his experiences on the Whole Earth 'Lectronic Link (WELL), Internet Relay Chat (IRC) channels, mailing lists, and many other online communities, Rheingold (1993; 2012) gave a historical vision of the way that social networks have grown to be more than just conduits for information but also pathways to human relationships. 


\section{Methodology}

VC continuously receives informal participant feedback during events through Twitter and from participant blogs. To complement the informal feedback, we initiated a survey of the pilot project titled \#et4buddy (Bali \& Hogue, 2015). Since the initial pilot project, which started with two participants (Maha and Rebecca), VC has evolved into a connected learning movement with over 50 event facilitators and over 200 active participants. In February and March 2016, we launched a second survey to evaluate the current state of VC which can be viewed at https://www.surveymonkey.com/r/VirtuallyConnecting. The survey targeted individuals who participated in VC as volunteers, guests, or conference organizers. The number of volunteers continues to grow - many people who start out as onsite or virtual guests later decide to become volunteers. The dynamics of our volunteers are addressed in more detail later in the discussion on volunteerism. The two-person team has evolved into a growing number of volunteers across global time zones. Many are active throughout the year, while others are active only for particular events because of personal interests or time zone restrictions.

This article looks at VC from two lenses while linking it to various educational learning theories:

1. The lens of our manifesto as presented at dLRN15. This was developed by a small group of us just ahead of dLRN15 as we struggled to make explicit our ethos and intentions while responding to criticism.

2. The lens of feedback from others who have participated in the VC movement, collected via survey feedback and from blogs and social media. The survey was sent out to anyone who had ever participated in VC in some form. Participants chose between being quoted by name and remaining anonymous, which is why not all respondent names are identified in the study results. We received 56 responses out of the 230 people we emailed.

As such, this article attempts to compare the theory and practice of VC. Our research questions are:

1. Do those who take part in VC perceive (as evidenced by the survey and elsewhere) its practice to be congruent with the intended ethos as expressed in our manifesto?

2. If VC is a form of hybrid networked/connected learning applied to conferences, how does the ethos of VC intersect with Connectivist, connected learning theory, and the practices of online learning communities?

The lines of participation and connection are blurred between who is 'in' and 'out' of this connected learning movement. There are those who join VC as 'guests', whether onsite or virtually, and there are those we call 'buddies'--onsite and virtual--who play active roles in organizing the sessions before, during and after they take place. The reason the lines are fuzzy and fluid is that very often, someone who participates as a guest in a few sessions will volunteer to become a buddy engaging in the backchannel organizational work. For example, when we conducted the survey, the organizational backchannel had approximately 50 team members; at the time of writing this essay, only a few months later, it has 69 members. In addition, there are some academic conference organizers who support VC as partners for their event but are not officially part of the VC team. All of these people received email invitations to respond to the 2016 survey. Unless otherwise stated, quotes in the following section are taken from the survey. Occasionally, we quote from blogs about VC and credit the authors. 


\section{Results and Discussion}

We begin by sharing survey demographic data (see Figure 1) and then follow with results sorted by relevance to each of our manifesto items (Virtually Connecting, undated), and finally we conclude with overall impression of the VC experience. Of the respondents, $67.1 \%(n=37)$ indicated that they have watched a VC live or a recorded hangout, $48.2 \%(n=27)$ indicated that they participated as onsite guests, $51.8 \%(n=29)$ indicated that they have participated as virtual guests, 17.9\% $(\mathrm{n}=10)$ indicated they were a conference organizer who has worked with VC, $30.4 \%(n=17)$ indicated they were a virtual buddy, 25\% $(n=14)$ indicated they were on onsite buddy, and 16.1\% (n=9) indicated that they were “Other buddy (e.g. tweeting, blogging)”.

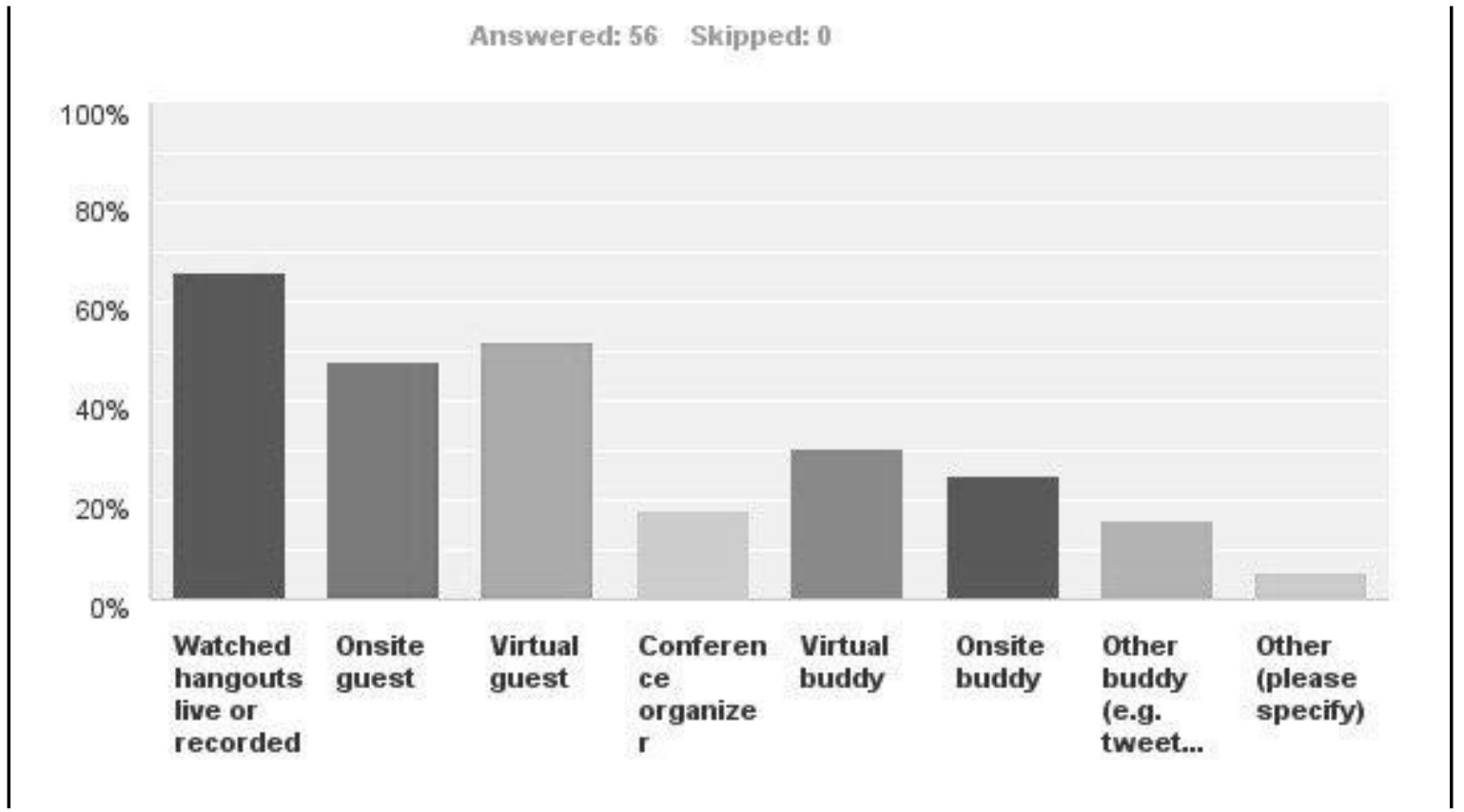

Figure 1. Response to question 2: "I have participated in Virtually Connecting in each of the following ways (select all that apply).

\section{Manifesto Item 1: Improve virtual experience}

We are motivated by a desire to improve the virtual conference experience for those who cannot be present at conferences for financial, logistical, social or health reasons. This often includes unaffiliated scholars, graduate students, adjuncts, moms of young kids, and people from developing countries or countries far away from where most academic conferences are held.

There is much to be learned by reflecting on Rheingold (1993; 2012) and Ito et al. (2013) in relation to manifesto item number 1 . This manifesto item is rooted in the relationship and power dynamics between those that are physically present in a space and those that are physically separated from one another but connected through technological means. In his book Virtual Communities: Homesteading in the Electronic Frontier, Rheingold (1993) reflects on how his lived experience participating in the online community the WELL was enhanced by 
physical encounters and mentions how those that lived outside of a specific physical location were limited in participation:

The WELL felt like an authentic community to me from the start because it was grounded in my everyday physical world. WELLites who don't live within driving distance of the San Francisco Bay area are constrained in their ability to participate in the local networks of face-to-face acquaintances... I can't count the parties and outings where the invisible personae who first acted out their parts in the debates and melodramas on my computer screen later manifested in front of me in the physical world in the form of real people, with faces, bodies, and voices. (Rheingold,1993)

While VC is not centered around any one physical location, this constraint in the ability to participate physically is deeply embedded into the meaning and importance behind manifesto item 1 . There seems to be a similar tension between the physical and the virtual that is present in both the WELL and VC. While the physically located conference becomes the temporal hub driving the VC sessions, it is the connections made possible at a distance that enable greater social ties from those from more diverse environments.

Connections are made in the VC video chats themselves but also in extensive communications that take place before and after the conference on social media. In the ways that social media make "new forms of sociality possible" (Rheingold 2012, p. 251), VC has done so for conferences by creating a presence on social media around the planned conversations as well as opening new lines of communication. Additionally, Rheingold stated that "networks that enable many-to-many communication grow in value more rapidly than broadcast networks" (2012, p. 251). This may explain why VC is more popular than livestreamed events.

The sentiment of manifesto item 1 is profoundly aware of the power dynamics that come with the work of VC. VC's approach to dealing with this power dynamic corresponds to the connected learning values as defined by Ito et al. (2013) of equity, full participation and social connection which provides insight into contexts for connecting learning, specifically peer supported, interest powered, academically oriented. As one survey respondent wrote:

The ability to connect with people at events I can't physically attend is very beneficial. If I'm joining a hangout then I have the ability to also meet and network with other attendees from the field, which makes it possible to grow my PLN [personal learning network] in different directions. The possibility of virtually meeting presenters and asking them questions also makes me feel like I'm not missing out on the whole experience if I'm joining the event only virtually.

Virtual attendance at academic conferences often comes with a lower expectation of possibilities around participation and collaboration. VC's manifesto item 1 intends to challenge this notion through community building around shared conversations.

\section{Manifesto Item 2: Inclusivity}

While our aim is to be inclusive, we recognize that inclusion is elusive. When others point out to us ways to be more inclusive we try them. We are trying to both support the 
development of social capital for people who cannot attend conferences, and to generously do so as widely as we are able. We try to welcome and create space for new people to participate. The way we have expanded means many who were participants are now part of the team and this creates more space for new participants as we widen our circle.

Manifesto item 2 highlights an association with the Connectivist principle, as outlined by Siemens (2004), which posited that "learning and knowledge rest in diverse opinions". VC supports this principle of Connectivism by enabling voices that would not otherwise be present at the conference to have an influence and to enable learning between those that are at the conference and those that are not. By allowing these other voices access to the conference conversation, we connect people from various backgrounds and create a diverse and inclusive experience. When asked what are the best things VC offers, one anonymous participant from our 2016 survey said that VC is "a way to connect people like never before. Making conferences more inclusive”. Other participants said things like "accessibility and extending conversations”, "access to conference I cannot travel to and access to speakers", and "access to conversations without geographical limitations”. Beyond the survey, several graduate students wrote about their experiences with VC. For example, participant Lisa Hammershaimb wrote:

As someone with very limited income, being part of Virtually Connecting has given me access to events that I otherwise would have no chance to attend. With this access comes pretty amazing content but even more comes invaluable exposure to the "human creator" that is behind every idea. This latter element is admittedly what I love the most. Three years of being a doctoral student means I am getting the hang of how you write as an academic, engage with ideas, etc. but...I'm still super curious as to how one actually lives as an academic.

Suzan Koseoglu (2015), a PhD student at the time, wrote of her experience meeting Gardner Campbell at et4online:

I had some questions in mind about "technology of emergence" vs "emergent technologies," something Dr. C. discussed in his plenary talk "Thought Vectors in Concept Space” earlier in the morning the same day and couldn't wait to talk to Dr. C about them. But at the same time I felt a bit shy and uneasy about being present "out in the open.” But I joined the hangout, asked my questions to Dr. C... and it was great. I just can’t describe the experience here. My experience in Turkish schools taught me to follow hierarchy and build it, even if doesn't impose any structures on me. But here I was talking to somebody influential in the field, asking some basic questions and getting answers.

In addition, one conference organizer says "VC provides the space for new connections to happen that might have otherwise not happened. As a conference organizer, VC also provides an excellent platform to further the reach and impact of the conference by promoting the conference/event to a different community and network who may not have been aware of the conference/event.” Another anonymous respondent said: 
What I love about VC is the way that it creates opportunities for connection and thrives on a connecting culture. VC uses technology to break down barriers that keep people from making those connections because of time, distance, money, etc. but sometimes the barriers are not with the technology or with some resource. Sometimes the barrier is within ourselves - just not feeling socially confident or having a low tech efficacy can be a huge barrier. I find many initiatives will not feel a responsibility to breaking these barriers down (especially social anxieties) but it seems like VC really cares about these things. The community works with one another to encourage new people.

However, we recognize that inclusion is elusive. As Cormier (2015) highlighted, "Every 'we' makes a 'them'”. As a result, any community is likely to make a few people feel excluded. Manifesto item 2 was created in response to some criticism that we received early on stating that VC felt like an "exclusive club" to some. An important reason for our 2016 survey was to explore how we could improve and expand VC. We got interesting results on Q7v of the survey when we asked participants whether they agreed with the statement that "VC feels like an exclusive club”. Figure 2 shows that while the majority, $70 \%(n=39)$, disagreed or strongly disagreed that there were $7 \%(n=4)$ who agreed, while $20 \%(n=11)$ felt unsure about this question. Responses like these help us to reflect on ways to become more inclusive and open to those who do not know us. One general guideline offered by a survey respondent was "Pay attention and actively welcome diverse voices and people”. Our process for inviting onsite and virtual guests (outlined below) attempts to be inclusive, but we recognize that it many ways it is not.

\section{VC feels like an exclusive club}

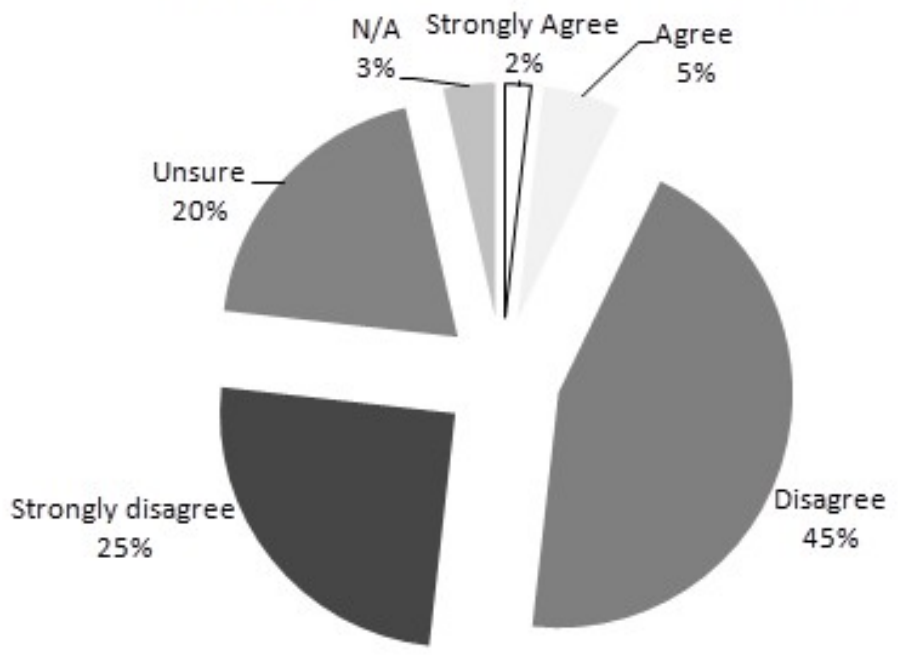

Figure 2. Q7v “VC feels like an exclusive club” results

Question Q7 allowed for comments; qualitative responses allowed us to understand at a deeper level those that responded to this survey question. One survey respondent, Joe Murphy 
(personal communication, 2016), explained his 'unsure' response as follows: "I think VC definitely feels like a club. I think it's a pretty inclusive club - but I can see why some people might just see the 'club' aspect of it and be too shy to find out how nice the people in it are.”

Side note: how does VC attempt to be inclusive?

$\mathrm{VC}$ is about trying to invite conference participants onsite and those virtually interested in the conversations.

Invitations to onsite guests

These are not usually organized in a particular way and can go any of the following ways

- VC members pick people they wish to meet onsite or virtually and invite them ahead of time (sometimes days or weeks in advance) on Twitter or by email to give us a time they can meet. If they are unfamiliar with VC, we share Hogue and Bali (2015) which described VC and has one sample session embedded:

- VC members put out an open call on Twitter before the conference "anyone going to conference X and wants to VC?” (this occasionally works; at dlrn15 we had a signup form for onsite as well as virtual participation but also invited specific people)

- Conference organizers recommend particular people to meet and help set up meetings

- A VC member systematically goes through participant/presenter list at an event and looks for people who haven't VCed before or who have interesting sessions

- During the event, onsite buddies can spontaneously invite someone new to a session (just before it starts or during if the person is interested as long as they understand it is livestreamed and recorded)

- Any combination of the above

The biggest barrier to onsite participants joining is not knowing what $\mathrm{VC}$ is. We try to remedy that by presenting a session about VC in some way at many events we attend, including a format called fishbowl where others can watch a session in progress, without having to be part of it - all because we recognize some people may not feel comfortable on camera or not wish to take time away from the conference. We respect people's wishes not to participate, but at the same time we try to welcome new people. Some onsite guests have been on VC multiple times because they enjoy it and virtual participants continue wanting to meet them even though it is often a different crowd of virtual participants each time.

\section{Invitations to Participate Virtually}

Usually, anyone who wishes to register virtually can either leave a comment on the blogpost announcing the schedule of VC at the event or tweet @vconnecting and ask to register. If someone interacts with a tweet about the event (favorite or retweet), we reach out to them and ask if they would like to join a session. When VC started and was less known, virtual participants were friends or acquaintances of buddies. Now it is highly likely for a session to have people who don't know each other at all. Google Hangouts as a tool has a limit of 10 people per session. We feel this is a reasonable number conducive to conversation; any bigger would be difficult, especially given that onsite participants can be two or more. When we receive more requests than we can accommodate, we place people on waiting lists and allow them to join if someone cancels. Usually people who are members of the VC team step down to make space for 
new participants. We recognize that access to all of this (a VC experience) is contingent upon a multitude of factors: virtual participants having good enough internet infrastructure, technical skills and literacies, English language fluency, and personalities willing to be livestreamed and recorded.

In looking at the principle of inclusivity, we asked the survey question "Q8: How can VC expand access". The top three responses were (1) $75.9 \%(n=41)$ more conferences in other countries, (2) more edtech conferences 53.7\% ( $n=29)$, and (3) more conferences in other fields $53.7 \%(n=29)$. At the time we wrote this article, VC had participated in conferences in the following countries: US, UK (England and Scotland), Canada, Belgium, Egypt, Italy, and Australia. We had only conducted one event outside of the ed tech field: an ePatients conference in the UK. Important caveats here are that expanding to fields beyond ed tech entail working with participants who possibly would be less tech-savvy. In the case of ePatients, the event was recorded but not livestreamed publicly to maintain privacy; participant consent was obtained after the fact to make the recording public.

\section{Manifesto Item 3: Participatory Experience}

Our focus is on conversation not content; we aim to create a participatory experience. Our goal is to go beyond the production of consumable media and provide an avenue for virtual and onsite people to converse directly with one another during the buzz and excitement of the conference. Many (though not all) of our conversations are live streamed and recorded for those looking to get a taste of the conversation who could not participate for whatever reason. While we appreciate conferences that stream sessions/keynotes and individuals that use live-stream apps and software (with permission) to capture these events, this is not our mission or focus.

Participatory values behind Connectivism, connected learning, and online communities revolve around connecting ideas and people through conversation between people and a decentering of content. This is explicit in Cormier's (2008) work regarding rhizomatic learning, where the community is the curriculum. In Connectivism, the potential to make connections is essential for learning. Intersections with the theory of Connectivism to the participatory experience item inside the VC manifesto can especially be seen specifically in the following principles of the theory as stated by Siemens (2004): "nurturing and maintaining connections is needed to facilitate continuous learning; learning is a process of connecting specialized nodes or information sources". In Q7iv, we heard from participants that VC helped expand their personal learning network (PLN)--91\% $(n=51)$ of respondents, even though many of them were already people well-connected in the field of educational technology in which we operate. According to survey respondent Martin Weller, VC succeeds in "promoting the status of virtual participation, offering discussion outside the conference which is as valuable as that in the situation, being lovely and friendly (sounds like a trite comment, but actually is key!).”

According to respondents of Q4, several of the best things VC offers are coupled with participatory experience including: “opportunities for networking and relationship building”, "connecting to discuss together", and "the ability to learn about other communities around the world who are engaged in teaching and learning”. One onsite participant responded: 
In addition to providing a forum for participation for virtual conference attendees, the option to join as a guest almost exceeds the on-site conference experience. Specifically, it has not been my experience to have allocated time to follow up with a keynote speaker, for example, to ask questions in a way that feels both intimate and engaging.

Another commented about a "sense of connection with the 'buzz' of a conference." This respondent stated:

Some of the most valuable parts of a conference are the chats outside of sessions conversations sparking off one another. VC gives this opportunity to virtual participants as well as enriching the experience for onsite participants who join in the conversations.

Enriching participatory learning experiences through engaging conversation is noted in several of the survey responses to Q4. One respondent stated that VC "establishes a friendly and warm tone at scholarly events and conferences", "allows less known people opportunities to chat with keynote speakers", "allows friends to connect during the buzz of conferences even when they can't be there”, and “allows people onsite to spend time having substantive conversations". Note how the last comment emphasized how VC enriches the onsite experience itself.

Participatory culture is essential in Rheingold's (2012) analysis of online communities as evidenced by his statement that "Casual conversation builds trust and enables more instrumental collaboration in all forms of networked collaboration" (p. 250) and again when he wrote "...small talk nourishes trust. Trust lubricates transaction" (p. 251).

In her (2015) blogpost, Suzan Koseoglu said:

Why would I go to a conference only to present a PowerPoint and listen to other PPTs? Why would I go to a conference if nobody is going to ask me any questions about my work, question it, and make suggestions to look at it from a different perspective? I've been to conferences where I almost begged for a discussion (in whispers). One time a friend commented that I liked asking questions (after listening to presentations). Here is my response after almost 3 years: How can you sit down for 20 to $30 \mathrm{~min}$. listening to somebody talk about something and not have a single question! Is that even possible?

In the early days of VC, Michael Berman (then a supporter, now an advisory buddy) blogged about how VC virtualize the "Right part of the conference":

[The] chance to ask a few questions and see the response is just marvelous. It's deeper and richer and more personal, and the slightly underground feeling adds an authenticity and appeal that draws you in. This is worth so much more than high def video with perfect lighting. People can speak naturally, and it's more like the karaoke bar than the Halo room.

\section{Manifesto Item 4: Volunteerism}

We are a team of volunteers. Everyone who is an onsite, virtual or blogging buddy is a volunteer. Volunteers are welcome to join us for a minute, a hangout, a conference, or become team members. We welcome new volunteers - join us here. We are committed to 
reducing the stress and effort of buddies, so we have started to encourage teams of onsite buddies to support each other and teams of virtual buddies to handle different logistics such as email, g+ and twitter, as well as the actual hangout management. This team approach fosters deeper connections between those involved in running virtually connecting.

VC aligns with Rheingold's (2012) description of a new social organization as having a "combination of free expression, lack of central control, many-to-many communication access, and volunteer effort” (p. 114). VC is an evolving connected learning experience with loosely connected nodes from those that simply watch from afar, those that participate but do not volunteer, to our group of volunteers who we refer to as 'buddies'. Buddies form a closer knit community of volunteers and identify themselves as members of VC and communicate privately largely through a backchannel on Slack. These volunteers can take on a variety of roles which may include any number of technical and affective skills. For instance, volunteers could find themselves hosting sessions, doing outreach using social media, or planning and logistics. One of the interesting aspects of $\mathrm{VC}$ is how by offering multiple opportunities over several different conferences, someone can go from engaging once or twice to becoming an active part of the community. As buddies become more involved, they acquire greater skills at seeing, making, and maintaining connections. They learn about other academics and professionals working in various disciplines and how they academically and socially connect with one another. On both a personal level and a topical level, they start to connect where they feel affiliation and affinity. We can see another link with Connectivism here in an alignment to the principle which calls out that the “ability to see connections between fields, ideas, and concepts is a core skill” (Siemens, 2004). VC, through our principle of volunteerism as stated in manifesto item 4, provides a platform of practice for people to learn how to see connections.

Although the purpose of $\mathrm{VC}$ is to enliven the virtual conference experience, the benefits of the VC team approach ensure that all participants gain from the experience, as attested to by this respondent to the 2016 survey: "as an onsite buddy, it prompted me to talk to people I might not because I carried my 'buddy' with me.” The deepening of network connections resulted from the focus on volunteerism to nurture a win/win relationship among participants.

\section{Manifesto Item 5: Non-disruptive}

We do not aim to disrupt the onsite experience - we aim to only take up a few minutes of an onsite person's (informal) time to offer it to those not privileged enough to attend the conference. This usually takes up part of one coffee break or lunch break. We do not intrude on social events (like receptions or dinners) unless offered to us. Joining is a choice, and any individual is free not to join (for whatever reason). We will never force an onsite or virtual person to join a hangout without their consent/willingness to do so and we will take steps to assure that bystanders are not caught in the video stream unknowingly.

Our intent to enliven the virtual conference experience has been misunderstood by some in regards to how it affects the onsite experience. Manifesto item 5 was created in direct response to criticism that VC disrupts the onsite conference experience. It was created to assure that as we continually develop processes that are actively considerate of this concern about disruption. 
When we developed our 2016 survey, we asked respondents to indicate their level of agreement with the statement "VC interrupts/disrupts face-to-face interaction" in Q7viii. No respondents strongly agreed with this statement, while $7.1 \%$ (n. 4) indicated that they agreed, 50\% (n. 28) indicated that they disagreed, $26.8 \%$ (n. 15) indicated that they strongly disagreed, $12.5 \%$ (n. 7) indicated that they were unsure, and $3.5 \%$ (n. 2) choose N/A.

In qualitative comments of the 2016 survey, members of the VC community expressed confusion to the disruption criticism, which is highlighted by Penny Bentley's question: "Why does it interrupt when it's voluntary...nobody is forcing anyone to participate in VC?” One anonymous survey respondent indicated confusion highlighting that face-to-face conferences are inherently disruptive:

I find it odd that people say that VC 'interrupts the face-to-face conference experience in disruptive ways.' F2F conferences are always interrupted and disrupted by the very people that are there - people always walk up and join in, or wander away, or whatever. Then there are the technical problems, the noise of other sessions, you name. I don't see how VC could be more disruptive than what already happens. I say, fully integrate VC into sessions.

These survey responses show alignment with this manifesto item.

Rather than being a disruptive presence at conferences, survey respondents see VC as a mutually beneficial experience. Alan Levine highlighted this when he commented:

It [VC] expands the conference experience in both directions- for those not physically at a conference, it brings the human experience closer in a way that live streams and tweet alone do not. For those physically at a conference, it provides a way to reflect/share about the conference. On both ends it creates a space to reinforce connections with people you know and to expand your network to people you may not know.

One digital literacy mentioned by Rheingold (2012) is focused attention. VC offers opportunities for virtual participants to focus their attention on a particular conversation versus the more chaotic Twitter stream. VC creates opportunities for onsite participants to spend some time conversing in-depth. If one thinks of a conference hallway as a third space/place, i.e. neither a fully social nor fully formal workspace, but somewhere in between, then VC becomes that hybrid third place. For some people, having a café in the middle of your workplace is inconvenient and unsuitable to a formal space; for others, as indicated by the majority of survey respondents, the hybrid third space is a welcoming environment for conversations that are neither too formal nor completely social. We recognize that those surveyed have participated in VC experiences in some capacity. It is possible that there are others who choose not to participate and find VC disruptive to onsite conference experiences. Efforts to avoid disrupting the onsite experience include seeking out quiet locations so others attending the conference event do not find themselves inadvertently on camera or recorded. While this helps us have a quiet hangout and disrupt the event less, those closed rooms make the meeting less hospitable to "drop ins". When we hold hangouts in hallways, we try to ensure there is a wall behind us so that no one passes by and gets recorded unintentionally. A pleasant side effect of being out in the hallway, 
however, is that others can observe from afar and sometimes ask to join the conversation. So, in a sense, trying too hard to avoid disrupting an event could result in our "informal" space appearing more formal and less welcoming to new ideas or participants. This becomes a decisional balance for VC volunteers relevant to manifesto item 2.

\section{Manifesto Item 6: Free Agency}

We consider ourselves to be free agents - While we welcome conference partnership (e.g. conferences organizers that mention us in sessions, give us space onsite with good wifi or space on their website or blog, or offer us free/reduced registration) we think of ourselves as guerilla connectors and we feel we are free to meet individuals at conferences without needing organizer permission.

From its roots, VC was an agreement between colleague-friends and has always been driven by the idea of colleagues that wanted to engage in learning conversations with each other despite distance. The conference provides an event in which to bring colleagues together. However, the conference organizers would never feel the need to give permission for colleagues to meet and debrief sessions in the hallway. VC does not see the need to obtain permission to use technology to facilitate a conversation outside of scheduled sessions between those that are separated physically at the conference. This is actually very similar to a lot of Connectivist MOOCs that tend to be individual volunteer efforts rather than formal, compensated, institutional projects. Also similar to Rheingold's (1993; 2012) literacy of participation culture - VC is made possible by the active participation of volunteers and not conference organizer planning.

This manifesto item of free agency can be tied back to the principle of knowledge capacity from the theory of Connectivism. This principle, stating that the "capacity to know more is more critical than what is currently known" (Siemens, 2004), highlights the importance of the ability to engage in a continual search for greater knowledge. While knowledge is advanced through research, it is also advanced through shared narrative driven forward by conversation. Engagement between those that would not otherwise be able to share knowledge at academic conferences due to disturbances should not be hampered, especially in public spaces. As a distributed, diverse, and connected group of free agents, our capacity for new knowledge as a networked whole is increased.

The manifesto item on free agency will be of particular note as VC continues to grow. It will be an important piece in regards to planning how we interact with conference organizers. In the 2016 survey, respondents were mixed in their reactions to how VC should partner with conference organizers. Jamison Miller indicated he would like VC to become a more formal part of conferences rather than an aside when he stated "I wish VC could become an active participant as a session (or the like) at the conferences. Right now it feels like just a few participants agree to an "aside" with VC, it still feels pretty apart from the rest of the goings ons." Penny Bentley explicitly said she does not want VC to "lose its grassroots feel." One anonymous participant felt the best thing about VC was the "opportunities to pierce the exclusive nature of expensive, distant conferences.” It is possible that some conference organizers would prefer to maintain some amount of exclusivity around their events, and VC will need to be guided by this manifesto item as we grow with the community. 


\section{Manifesto Item 7: Criticism}

We are open to constructive criticism and suggestions for improvement. Constructive criticisms of this manifesto; our values, motives, and goals as well as of our onsite and virtual practices are welcomed. We are looking to continually improve. We ask that these are worded in ways that would not be conceived as personal attacks.

The 7th VC manifesto item concerning criticism can be found deeply embedded in our decision-making processes and can even be evidenced by this very manifesto. We use criticism to grow in an environment that is ever-changing. Siemens (2004) principle of Connectivism which stated:

Decision-making is itself a learning process. Choosing what to learn and the meaning of incoming information is seen through the lens of a shifting reality. While there is a right answer now, it may be wrong tomorrow due to alterations in the information climate affecting the decision.

The above highlights the importance of this item. VC recognizes that our movement is an emergent one. Our plan for improvement is to focus on receiving feedback from those that are involved in, as well as from those that are observing, our practices and to reflect upon and change based on an iterative process. Several items in our manifesto were created as a result of our response to criticism. This is evidenced specifically inside of manifesto items 2, 5, and 6.

VC's approach to criticism requires that the VC Manifesto itself continues as a fluid document that can address the ever-changing nature of the emerging movement. VC itself, as a connected learning movement, is a 'non-human' entity that itself can be said to learn - adapting to changes in its operating environment. Here we associate with Siemens (2004) principle of Connectivist learning theory stating that "Learning may reside in non-human appliances.” By using the manifesto as a guiding document for decision making, we follow the ethos as defined by the community; by allowing for revisions to the document, we allow ourselves to grow with our environment.

\section{Manifesto Item 8: Imperfection}

We aim to have fun and embrace spontaneity and imperfection We recognize this kind of thing isn't fun or accessible for everyone.

Our final manifesto item highlights spontaneity and imperfection in order to help demonstrate the 'normalness' of the conversation. Our goal is not to replicate polished presentations but rather to provide a venue for the learning that occurs through informal conversations. As a result, we value currency of knowledge over a polished delayed experience. This item aligns with Siemens (2004) theory of Connectivism in the principle that states, "Currency (accurate, up-to-date knowledge) is the intent of all Connectivist learning activities". By privileging immediacy over cultivated media production values, we aim to facilitate authentic conversational experiences. This was noticed and well-received by respondents to our 2016 survey. One anonymous survey-taker, when asked about the best thing about VC, stated "Spontaneity - I was at OLC15 and had the opportunity to join briefly in a Hangout. Loved the spontaneous ability to connect.” In Q5 when asked what VC should continue doing, an 
anonymous respondent stated "continue inviting people; allowing spontaneous drop-ins. The planning ahead is great, but spontaneity rocks." Alan Levine expressed "Keep it low key and spontaneous, most of the sessions I remember best were ones that were not overly choreographed."

\section{Overall Impressions of VC}

We have just reviewed how responses from the VC community in our 2016 survey aligned with our manifesto items. Finally, we will report on the overall impressions of VC from the survey. Q3 asked respondents "How has your overall experience with VC been?" Answers to Q3 are charted in Figure 3 and show that the majority of respondents had a mostly positive experience with VC at $84 \%$ (n.47), with 11\% (n. 6) having mixed experiences of some good hangouts and some less-than-good ones, and only 8\% (n. 3) having had lukewarm experiences. None of the respondents had mostly negative experiences with VC. We recognize that those who have had mostly negative experiences are less likely to have completed the survey.

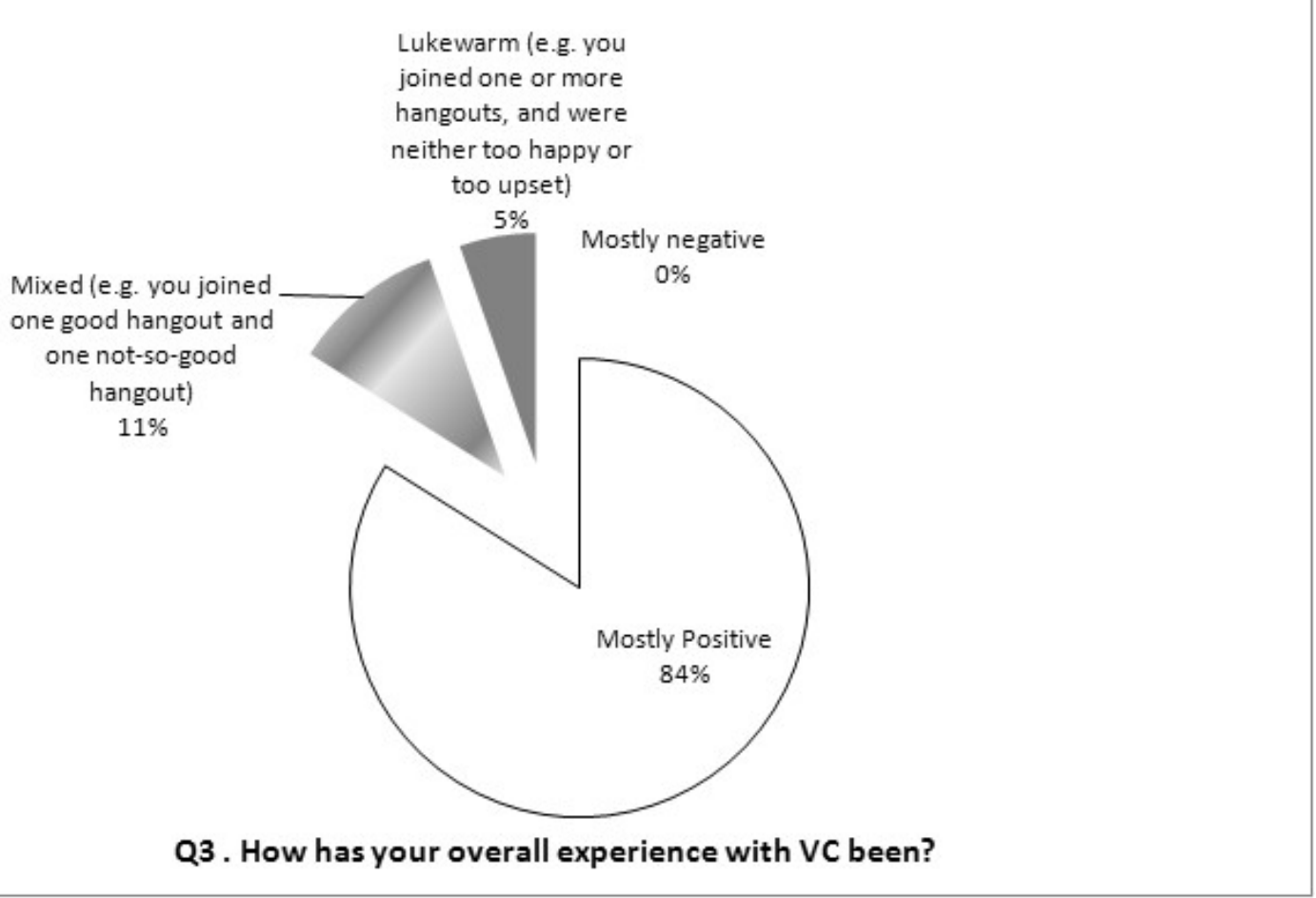

Figure 3. Q3: How has your overall experience with VC been?

\section{Conclusion}

In the earlier sections of this discussion, we linked responses to the $2016 \mathrm{VC}$ survey to each of the eight items from the VC manifesto and made further ties to connected/networked learning theories and theories around online communities. Hence, one could say that VC is a living enactment of Connectivist/connected learning theory applied to hybrid conferencing in community instead of online learning. 
We explored the VC Manifesto as presented at the dLRN 2015 conference and how it intersects with the theories of Connectivism, connected learning, and the practice of online communities as defined by Rheingold. We have also shown that, according to survey results, VC is in alignment with this manifesto. As noted, VC's manifesto is a living document that will change along with the changing nature of the movement. In 2016, VC formed a board of Advisory Buddies who will help to guide these changes to the manifesto. As stated by Reigeluth (2008) "For a system to be healthy, it must co-evolve with its environment: it changes in response to changes in its environment, and its environment changes in response to its changes”. We have begun, in small ways, to see some of those changes in the environment that VC functions in - the online conference experience. By creating a richer online experience for virtual participants, VC has begun to help conference organizers recognize the value in online participation. Many are now embracing our ethos as articulated in our manifesto and partnering directly with us to create an embedded experience.

\section{References}

Bali, M. \& Hogue, R. (2015, May 8). Virtual, hybrid, or present: The ET4Buddy experiment. Hybrid Pedagogy. Retrieved from http://www.digitalpedagogylab.com/hybridped/

Berman, M. (2015). Virtualizing the right part of the conference [Web log post]. Retrieved from: http://virtuallyconnecting.org/guest-post/virtualizing-the-right-part-of-the-conference/

Connected Learning Alliance (n.d.). Why Connected Learning. Retrieved from: http://clalliance.org/why-connected-learning/

Cormier, D. (2015). Community learning - Every 'we' makes a 'them'. [Webl og post]. Retrieved from:

http://davecormier.com/edblog/2015/08/27/community-learning-every-we-makes-a-them/

Cormier, D. (2008, June 3). Rhizomatic education: Community as curriculum. [Web log post]. Retreived from:

http://davecormier.com/edblog/2008/06/03/rhizomatic-education-community-ascurriculum/

Djuricich, A.M., \& Zee-Cheng, J. E. (2015). Live tweeting in medicine: 'Tweeting the meeting'. International Review of Psychiatry, 27(2). DOI: $\underline{\text { 10.3109/09540261.2014.1000270 }}$

Hammershaimb, L. (2016). On blank spaces, being human, and the amazingness of Virtually Connecting [Web log post]. Retrieved from: http://virtuallyconnecting.org/guest-post/on-blankspaces-being-human-and-the-amazingness-of-virtually-connecting/

Hogue, R. J., \& Bali, M. (2015, June 15). Beyond twitter: Virtually Connecting at conferences. Prof Hacker blog, Chronicle of Higher Education. Retrieved from: http://chronicle.com/blogs/profhacker/ 
Ito M., Gutiérrez, K., Livingstone, S., Penuel, B., Rhodes, J., Salen, K., Schor, J., Sefton-Green, J., \& Watkins, C. (2013). Connected learning: An agenda for research and design. Digital Media and Learning Research Hub, Irvine, CA. Retrieved from http://eprints.lse.ac.uk/48114/1/ lse.ac.uk_storage_LIBRARY Secondary_libfile_share d_repository_Content_Livingstone,\%20S_Livingstone_Connected_learning_agenda_201 $\underline{0}$ _Livingstone_Connected_learning_agenda_2013.pdf

Koseoglu, S. (2015). Thoughts on open pedagogy [weblog post]. Retrieved from: http://virtuallyconnecting.org/guest-post/thoughts-on-open-scholarship/

McIntyre, E., Millar, S., \& Thomas, F. (2007). Convening a conference--facilitating networking among delegates. Australian Family Physician, 36(8), 659-660.

Reigeluth, C. M. (2008). Chaos theory and the sciences of complexity: Foundations for transforming education. In B. Despres (Ed.), Systems Thinkers in Action: A Field Guide for Effective Change Leadership in Education. New York: Rowman \& Littlefield.

Rheingold, H. (1993). The virtual community: Homesteading on the electronic frontier. Reading, PA: Addison Wesley Publishing Company:. Retrieved from http://www.rheingold.com/vc/book/

Rheingold, H. (2012). Net smart: How to thrive online. Cambridge, MA: MIT Press.

Shiffmann, D. S. (2012). Twitter as a tool for conservation education and outreach: What scientific conferences can do to promote live-tweeting. Journal of Environmental Studies and Sciences, 2(3), 257-262.

Siemens, G. (2004, December 12). Connectivism: A learning theory for the digital age. [Web log post]. Retrieved from: http://www.elearnspace.org/Articles/connectivism.htm

Virtually Connecting (n.d.). Virtually Connecting Manifesto. Retrieved from http:/virtuallyconnecting.org/virtually-connecting-manifesto/ 